\title{
VULNERABILIDADE DA PAISAGEM ÀPERDA DE SOLOS DO MUNICÍPIO DE FRANCISCO SÁ - MG
}

\author{
VULNERABILITY OF THE LANDSCAPE MUNICIPALITYOF \\ FRANCISCO SÁ IS SOIL LOSS
}

\section{VULNERABILIDAD DEL PAISAJE DE LA MUNICIPIO DE FRANCISCO SA ES PÉRDIDA DE SUELO}

\author{
Maria Tereza Pereira dos Santos \\ Universidade Estadual de Montes Claros - UNIMONTES \\ E-mail: <mary.there1993@gmail.com>. \\ Maria Ivete Soares de Almeida \\ Universidade Estadual de Montes Claros - UNIMONTES \\ E-mail: <ivete.almeida@unimontes.br>.
}

\begin{abstract}
RESUMO
Dentre os problemas ambientais que atualmente ocorrem, a vulnerabilidade da paisagem à perda de solos é um dos que merece significativa atenção, devido aos danos irreversíveis causados à paisagem. Assim, este trabalho propõe determinar a vulnerabilidade da paisagem do município de Francisco Sá (MG) para a perda de solos, pautando-se na metodologia proposta por Crepaniet al. (2001). A partir dessa metodologia e com o uso das ferramentas geotecnológicas, foram elaborados mapas de vulnerabilidade para os elementos que compõem a paisagem (geologia, geomorfologia, solos, clima e uso do solo). Após a determinação da fragilidade de cada elemento, criou-se o produto cartográfico final de vulnerabilidade da paisagem, a partir do cruzamento de todas as variáveis. Como resultado, é possível afirmar que a paisagem do município de Francisco Sá apresenta vulnerabilidade de média à alta para a perda de solos o que, para tanto, foram considerados como principais fatores para essa constatação, os tipos de solos ali predominantes e seus respectivos usos.
\end{abstract}

Palavras-chave: Vulnerabilidade. Perda de solos. Geotecnologias.

\section{ABSTRACT}

Among the currently assisted environmental problems, the vulnerability of the landscape to soil loss is one that deserves attention. Thus, this paper proposes to determine the vulnerability of the landscape of the municipality of Francisco Sá to soil loss, based on the 
methodology proposed by Crepani et al. (2001). Based on this methodology and using geotechnological tools, vulnerability maps were prepared for the elements that make up the landscape (geology, geomorphology, soils, climate and land use) and, after determining the fragility of each element, were created. The final vulnerability chart of the landscape with the crossing of all variables. As a result, it is possible to state that the municipality of Francisco Sá presents medium to high vulnerability to soil loss, which were considered as main factors the predominant soil for this finding, types and their respective uses.

Keywords: Vulnerability. Loss of soil. Geotechnologies.

\section{RESUMEN}

Entre los problemas ambientales asistidos actualmente, la vulnerabilidad del paisaje a la pérdida de suelo merece atención. Así, este trabajo propone determinar la vulnerabilidad del paisaje del municipio de Francisco Sá a la pérdida de suelo, con base en la metodología propuesta por Crepani et al. (2001) Con base en esta metodología y el uso de herramientas geotecnológicas, se prepararon mapas de vulnerabilidad para los elementos que componen el paisaje (geología, geomorfología, suelos, clima y uso del suelo) y, después de determinar la fragilidad de cada elemento, se crearon. El gráfico de vulnerabilidad final del paisaje con el cruce de todas las variables. Como resultado, es posible decir que el paisaje del municipio de Francisco Sá presenta una vulnerabilidad de mediana a alta a la pérdida de suelo, que se consideraron como factores principales para este hallazgo, los tipos predominantes de suelos y sus respectivos usos.

Palabras clave: Vulnerabilidad. Pérdida de suelo. Geotecnologías.

\section{INTRODUÇÃO}

No atual cenário em que se vive, tem-se observado o expressivo aumento da degradação dos recursos naturais, como a exploração de forma predatória, o que vem causando um contexto de desequilíbrio na paisagem. Essa degradação é resultado da carência de informações sobre o meio físico-natural, aliado a práticas degradacionais, o que potencializam a vulnerabilidade ambiental de determinadas áreas. Entende-se como vulnerabilidade ambiental a maior ou menor suscetibilidade de um determinado ambiente a sofrer um impacto potencial, advindo de suas próprias características físicas ou uso antrópico. Assim, pode ser avaliada de acordo com vários critérios ou variáveis (TAGLIANI, 2003).

De acordo com Silva Neto e Aleixo (2016, p.255), a vulnerabilidade ambiental é a "ausência de condições que sustentam a integridade da estrutura e dinâmica de uma determinada paisagem, resultando em mudanças e transformações representativas no contexto da totalidade". Nessa perspectiva, a vulnerabilidade ambiental compreende a predisposição de 
SANTOS, M. T. P.; ALMEIDA, M. I. S.

Vulnerabilidade da paisagem à perda de solos do município de Francisco Sá - MG

um determinado ambiente a sofrer alterações, as quais poderão desequilibrá-lo quando exposto a uma determinada ação humana.

Por ser considerado um problema cada vez mais recorrente no meio ambiente, a vulnerabilidade à perda de solos merece indispensável atenção e cuidados, pois consiste no desprendimento e carregamento de suas partículas pela ação da água e do vento. Essa perda é um processo natural que ocorre em toda a superfície terrestre e, aliada a outros processos naturais, responsabiliza-se pela modelagem do relevo terrestre. Porém, com a ação antrópica nomeio ambiente, tais como, a retirada da cobertura vegetal para o uso agropecuário, exploração de recursos minerais e construção de áreas urbanas, os processos erosivos são intensificados (VALLE JUNIOR, 2008; GUERRA; MENDONÇA, 2005).

Os principais fatores que aceleram o processo de perdas do solo na paisagem decorrem das alterações não planejadas no uso da terra, associadas a uma determinada paisagem por vezes acima da capacidade de suporte do solo (GUERRA; CUNHA, 1996). O desrespeito às limitações físico-naturais dos ambientes vulneráveis é outro agravante. É provocado por uma incompatibilidade do uso da terra com determinado espaço em que se processa a utilização imprópria para o desenvolvimento de atividades, tais como, a pecuária e agricultura. Como exemplo dessas áreas vulneráveis destacam-se as detentoras de um relevo fortemente dissecado ou, ainda, aquelas nas quais os solos são rasos e suscetíveis à erosão (SILVA NETO, 2013).

Por outro lado, a busca desenfreada por lucros promove uma incompatibilidade entre o tempo de recomposição da natureza e a velocidade que ocorre a exploração dos recursos naturais, na maioria das vezes, de forma acelerada. Como consequência, a geração de expressivas transformações na paisagem as quais, em muitos casos e localidades, são irreversíveis (SUERTEGARAY; NUNES, 2001).

Nesse aspecto, as paisagens atuais são resultados das dinâmicas em que a relação sociedade e natureza acontecem de maneira mais intensa e degradante. Essa configuração de uso e ocupação provoca, então, novas paisagens, a partir da inserção de novos elementos ditadores, de novas formas e processos das paisagens atuais (SILVA NETO; ALEIXO, 2016).

Assim, a vulnerabilidade das paisagens à perda de solos é considerada como uma ruptura provocada pela intervenção da sociedade na natureza, cujo resultado se apresenta em uma nova organização das formas espaciais que se concretizam na paisagem (SILVA NETO; ALEIXO, 2016). 
SANTOS, M. T. P.; ALMEIDA, M. I. S.

Vulnerabilidade da paisagem à perda de solos do município de Francisco Sá - MG

Dessa forma, estudos voltados a entender a dinâmica da paisagem e sua vulnerabilidade são defendidos como imprescindíveis nesse contexto. Isso porque, ao identificar a vulnerabilidade da paisagem à perda de solos, tem-se um subsídio importante para tomadas de decisões por parte dos órgãos públicos. Assim se possibilita explicar essa ocorrência, uma vez que se oportuniza o conhecimento de quais áreas do território são adequadas ou não para utilização nas construções civis, na agricultura, na pecuária e nos sítios urbanos, entre outros. Outro importante fator é a possibilidade de se identificaras áreas de maior vulnerabilidade e, a partir daí, viabilizar que essas recebam uma atenção especial, de forma a se evitar possíveis danos ao ambiente natural (COSTA et al., 2006).

Para a identificação da vulnerabilidade da paisagem, o uso das ferramentas do Sistema de Informações Geográfica (SIG) se apresenta como um importante aliado, pois facilita os processos de tomada de decisões, além de conferir qualidade aos produtos elaborados(ROCKETT ET AL., 2014). Assim, a utilização do SIG torna possível realizar a integração dos aspectos físico-naturais tais como, solos, geomorfologia, clima e embasamento geológico. Essa integração é crucial para a elaboração da carta de vulnerabilidade à perda de solos. Tal procedimento, quando se objetiva analisar as modificações ocasionadas pelas alterações humanas sobre esse meio, permite viabilizar a melhor gestão do território (NICOLAU, 2018). Nessa perspectiva, o presente trabalho objetivou analisar a vulnerabilidade da paisagem do município de Francisco Sá à perda de solos, com base na integração dos seus elementos físico-naturais. Para tanto, utilizou-se a metodologia proposta por Crepani et al. (2001).

\section{MATERIAIS E MÉTODOS}

\section{Caracterização de área}

O município de Francisco Sá, em Minas Gerais (FIGURA 01) está situado entre as coordenadas $16^{\circ} 48.976^{\prime} \mathrm{S}$ e $43^{\circ} 29.346^{\prime} \mathrm{O}$ ao $\mathrm{Sul}$, e $16^{\circ} 4.370^{\prime} \mathrm{S}$ e $43^{\circ} 26.571^{\prime} \mathrm{O}$ ao Norte. Ocupa uma área territorial de $2.759 \mathrm{~km}^{2}$ e possui uma população de 24.912 habitantes dos quais, 40,2\% residem na área rural, ou seja, 10.015 habitantes. Enquanto isso, 14.897 habitantes residem na área urbana, o que corresponde a $59,8 \%$ de toda a população (INSTITUTO BRASILEIRO DE GEOGRAFIA E ESTATÍSTICA - IBGE, 2010). 
SANTOS, M. T. P.; ALMEIDA, M. I. S.

Vulnerabilidade da paisagem à perda de solos do município de Francisco Sá - MG

O município objeto de análise é composto por sua sede, dois distritos - Catuni e Cana Brava -, e várias comunidades rurais. Geograficamente limita-se com Montes Claros, Capitão Enéas, Janaúba, Riacho dos Machados, Grão Mogol, Itacambira e Juramento (IBGE, 2010).

Figura 01 - Mapa de localização do município de Francisco Sá

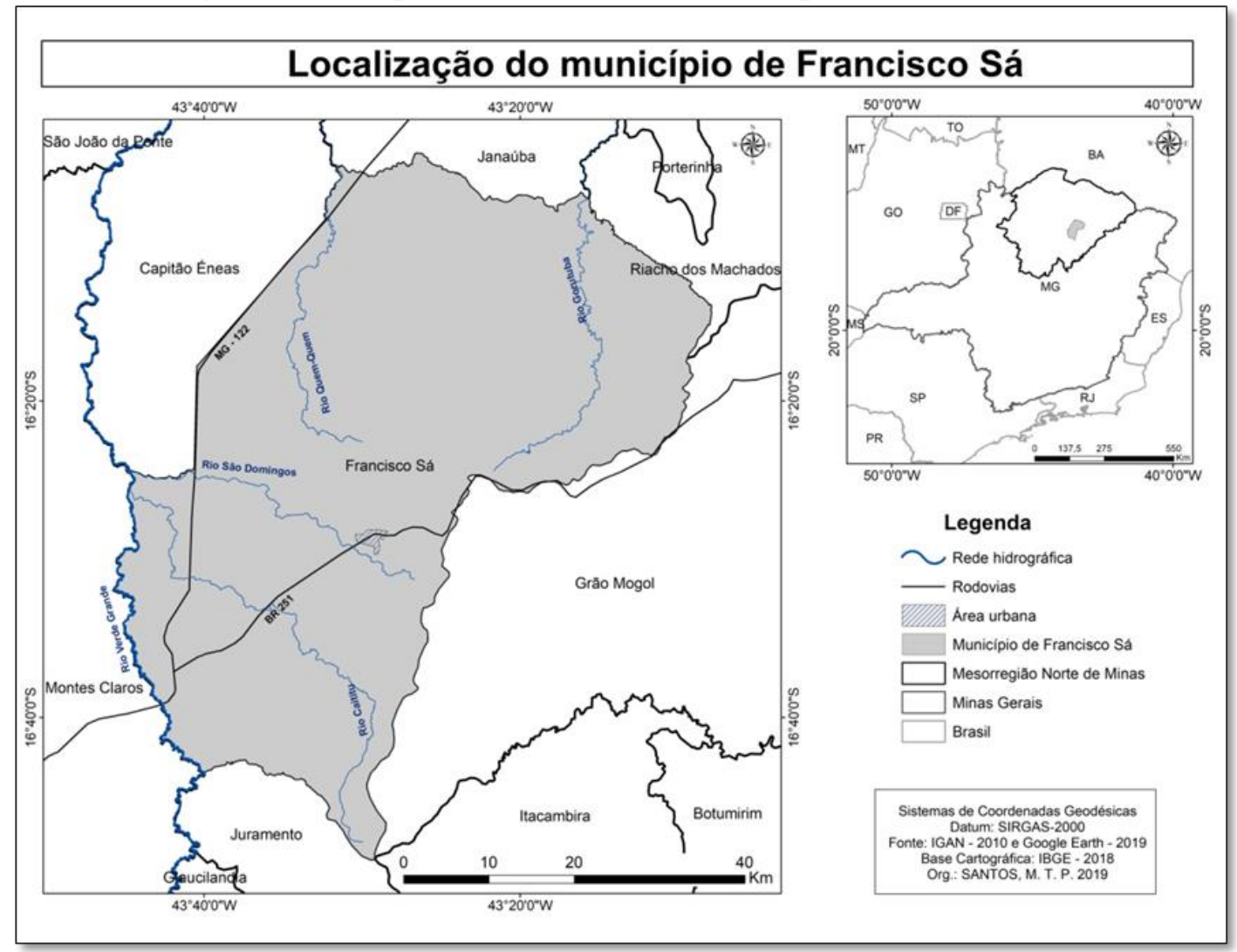

Fonte: SANTOS, M. T. P. (2019).

O município está inserido na mesorregião Norte de Minas, área de vulnerabilidade devido às suas características climáticas (FREITAS, CALHEIROS e REIS, 2019). A região está inserida numa área de transição do clima tropical semiúmido para semiárido. Devido à sua localização geográfica, há predomínio de um regime pluviométrico marcado por baixas precipitações ao ano, que variam de 500 a $800 \mathrm{~mm}$ de forma concentrada em seis meses do ano - de outubro a março -, e os outros seis meses - de abril a setembro -. A população norte mineira, então, convive com a estiagem que se impõe, em parte. Não obstante, às limitações às atividades econômicas e aos problemas com a escassez hídrica (SANTOS; LEITE, 2010, p.1-2). 
SANTOS, M. T. P.; ALMEIDA, M. I. S.

Vulnerabilidade da paisagem à perda de solos do município de Francisco Sá - MG

Segundo o IBGE (2002), o clima predominante no município de Francisco Sá pode ser definido como tropical semiúmido, com 4 a 5 meses secos e temperatura média superior a $18^{\circ} \mathrm{C}$ em todos os meses do ano, e com verões chuvosos e invernos secos. $\mathrm{Na}$ litologia da área é possível verificar a ocorrência de diversos grupos e formações rochosas, cuja maior parcela varia entre rochas sedimentares e metamórficas. A área pode ser dividida em dois grandes conjuntos de estruturas rochosas: rochas do embasamento pré-Macaúbas, Complexo Córrego do Cedro, Suíte Rio Itacambiruçu e Grupo Riacho dos Machados em um; no outro, rochas metassedimentares, Macaúbas e Bambuí (GUIMARÃES; GROSSI-SAD; FONSECA, 1997).

O município de Francisco Sá situa-se sobre duas unidades geomorfológicas: Bacia Sedimentar do São Francisco, subdividida em Superfícies aplainadas Flúvio-lacustre e Zonas de Colinas e Rampa de Contato; na outra, Serras, Patamares e Escarpas do Espinhaço, que apresentam os Planaltos de cimeira e Encostas e desníveis dos Planaltos (CPRM, 2010).

Hidrograficamente é drenado pelos seguintes rios afluentes do Rio Verde Grande da margem direita: Caititu, São Domingos, Quem-Quem e o Gorutuba (FIGURA 01). Apesar de apresentar uma rede de drenagem bastante significativa, seus cursos d'água são, em sua maioria, intermitentes - característica dos rios da região -, devido ao regime pluviométrico predominante (IGAM, 2010).

Quanto à pedologia do município, encontram-se as seguintes ocorrências: na porção central e na região mais ao leste, solos avançados e ricos em alumínio; já na parte central e estendendo-se para o norte e sul, os solos aluminosos, porém, pouco desenvolvidos, como se observa ao longo do vale do rio Gorutuba (GUIMARÃES; GROSSI-SAD; FONSECA, 1997).

Em relação à vegetação, o município de Francisco Sá está totalmente inserido no domínio do bioma Cerrado, caracterizado pela diversidade de fitofisionomias com formações florestais, savânicas e campestres. Essa diversidade é resultado de duas estações climáticas bem definidas, sendo uma úmida, no período de novembro a março; e uma seca, de abril a outubro (SCOLFORO et al., 2006). Embora os solos em sua maioria sejam considerados pobres e necessitem de correção, o domínio do Cerrado apresenta características da flora bastante rica (COUTINHO, 2006). 
SANTOS, M. T. P.; ALMEIDA, M. I. S.

Vulnerabilidade da paisagem à perda de solos do município de Francisco Sá - MG

\section{Procedimentos metodológicos}

O presente trabalho foi pautado na revisão bibliográfica para suporte teórico do tema discutido e na metodologia proposta por Crepani et al. (2001), cujos procedimentos baseiam-se no conceito de Ecodinâmica de Tricart (1977). Esse mesmo autor prioriza a relação morfogênese/pedogênese que, em conjunto com as análises realizadas por imagens de satélite, permite uma visão sinóptica e holística da paisagem (CREPANI et al., 2001). A classificação de vulnerabilidade das Unidades Territoriais Básicas (UTB'S) propostas por Crepani et al.(2001)considera os princípios da Ecodinâmica de Tricart (1977), que criam três categorias morfodinâmicas.

Essas categorias são classificadas como meios estáveis, caracterizados pela presença de cobertura vegetal densa, dissecação do relevo moderada e a não ocorrência de atividades vulcânicas (crepani et al., 2001). Concernente aos meios intermediários, como o resultado do balanço entre as interferências morfogenéticas e pedogenéticas. Já os meios fortemente instáveis são aqueles marcados por condições bioclimáticas agressivas, tais como, a presença de ventos e chuvas com variações fortes e irregulares, relevo dissecado intensamente, ocorrência de solos rasos, falta de cobertura vegetal densa, suscetibilidade de planícies e fundos de vales a inundações e, ainda, intensa geodinâmica interna (CREPANI et al., 2001). Com base nos princípios citados, foi criado um modelo para a avaliação da evolução morfodinâmica das Unidades Territoriais Básicas (UTB'S)e atribuiu-se valores de estabilidade às categorias morfodinâmicas, conforme disposto na Tabela 01.

Tabela 01 - Avaliação da estabilidade das categorias morfodinâmicas

\begin{tabular}{ccc}
\hline Categoria morfodinâmica & Relação Pedogênese/Morfogênese & Valor \\
\hline Estável & Prevalece a Pedogênese & 1,0 \\
Intermediária & Equilíbrio Pedogênese/Morfogênse & 2,0 \\
Instável & Prevalece a Morfogênese & 3,0 \\
\hline
\end{tabular}

Fonte: Crepani et al. (2001); SANTOS, M. T. P. (2019).

A partir da primeira classificação, elaborou-se uma escala com o propósito de contemplar uma maior variedade de categorias morfodinâmicas. O intuito era construir uma escala de vulnerabilidade para situações de origem natural. O modelo desenvolvido, a partir da primeira classificação, propõe 21 níveis de vulnerabilidade à perda de solo que se distribui 
SANTOS, M. T. P.; ALMEIDA, M. I. S.

Vulnerabilidade da paisagem à perda de solos do município de Francisco Sá - MG

por situações em que ocorrem predominantemente processos de pedogênese, conforme se visualiza na Tabela 02 .

Tabela 02 - Classificação de Vulnerabilidades das UTB's

\begin{tabular}{ccccc}
\hline Unidade da Paisagem & \multicolumn{2}{c}{ Valor da análise morfodinâmica } & Grau de Vulnerabilidade \\
\hline UTB 1 & & 3,0 & & \\
UTB 2 & & 2,9 & & Vulnerável \\
UTB 3 & & 2,8 & & \\
UTB 4 & e & 2,7 & $\mathrm{E}$ & Moderadamente \\
UTB 5 & $\mathrm{d}$ & 2,5 & $\mathrm{~s}$ & vulnerável \\
UTB 6 & $\mathrm{a}$ & 2,4 & $\mathrm{t}$ & \\
UTB 7 & $\mathrm{d}$ & 2,3 & $\mathrm{a}$ & \\
UTB 8 & $\mathrm{i}$ & 2,2 & $\mathrm{~b}$ & Medianamente \\
UTB 9 & $\mathrm{l}$ & 2,1 & $\mathrm{i}$ & estável/vulnerável \\
UTB 10 & $\mathrm{i}$ & 2,0 & $\mathrm{l}$ & \\
UTB 11 & $\mathrm{b}$ & 1,9 & $\mathrm{i}$ & \\
UTB 12 & $\mathrm{a}$ & 1,8 & $\mathrm{~d}$ & \\
UTB 13 & $\mathrm{r}$ & 1,7 & $\mathrm{a}$ & Moderadamente \\
UTB 14 & $\mathrm{e}$ & 1,6 & $\mathrm{~d}$ & estável \\
UTB 15 & $\mathrm{n}$ & 1,5 & $\mathrm{e}$ & \\
UTB 16 & $\mathrm{l}$ & 1,4 & & \\
UTB 17 & $\mathrm{u}$ & 1,3 & & Estável \\
UTB 18 & $\mathrm{V}$ & 1,2 & & \\
UTB 19 & & 1,1 & & \\
UTB 20 & & 1,0 & & \\
UTB 21 & & & & \\
\hline
\end{tabular}

Fonte: Crepani et al. (2001); SANTOS, M. T. P. (2019).

Assim, a metodologia proposta por Crepani et al. (2001) considera para geração do mapa de Vulnerabilidade da Paisagem à Perda de Solo, cada elemento - Geologia, Geomorfologia, Solo, Uso da Terra e Clima -. Esses recebem um valor final de vulnerabilidade, resultado da equação de média aritmética dos seus valores individuais, assim demonstrado:

\section{$\underline{V}=G+R+S+V g+C$}

$\mathrm{V}=$ Vulnerabilidade da Paisagem;

$\mathrm{G}=$ Vulnerabilidade Geológica;

$\mathrm{R}=$ Vulnerabilidade Geomorfológica;

$\mathrm{S}=$ Vulnerabilidade Pedológica; 
SANTOS, M. T. P.; ALMEIDA, M. I. S.

Vulnerabilidade da paisagem à perda de solos do município de Francisco Sá - MG

$\mathrm{Vg}=$ Vulnerabilidade vegetal e uso da terra;

$\mathrm{C}=$ Vulnerabilidade Climática.

Portanto, para a confecção da Carta de Vulnerabilidade à Perda de Solos do município de Francisco Sá utilizou-se o Modelo Digital de Elevação (MDE) na escala de 1:250.000, cuja resolução espacial é de 30 metros. Esse modelo é oriundo da Missão Topográfica Radar Shuttle (SRTM), disponibilizada sem custos no sítio da Empresa Brasileira de Pesquisa Agropecuária (EMBRAPA), especificamente as cartas SE-23-X-A e SE-23-X-B.

No que se refere à Base Cartográfica com limites territoriais do Brasil - ano de 2018 -, essa foi viabilizada por meio do sítio eletrônico do IBGE. A Carta Geológica de Minas Gerais do ano de 2010 foi então adquirida junto ao sítio da Companhia de Pesquisa de Recursos Minerais (CPRM) e o Mapa de Solos do Estado de Minas Gerais no sítio do Departamento de Solos Centro de Ciências Agrárias (DPS) da Universidade Federal de Viçosa (UFV).

Quanto aos dados pluviométricos do município, esses foram adquiridos junto à EMATER daquela localidade. Por fim, a imagem de satélite do sensor OLI do satélite Landsat8 do ano de 2019, localizada na órbita 218 e pontos 071 e 072, disponível no sítio do Instituto Nacional de Pesquisas Espaciais (INPE).

Após a obtenção dos materiais necessários, foram utilizadas as ferramentas do software ArcGis na versão 10.5, licenciado pelo Laboratório de Geoprocessamento da Universidade Estadual de Montes Claros (UNIMONTES), com as quais foram confeccionados os mapas bases (geologia, geomorfologia-declividade, solos, uso do solo e clima). Por conseguinte, com base na classificação de vulnerabilidades proposta por Crepani et al. (2001), atribuíram-se valores a cada uma das classes, conforme a Tabela 03. Na última etapa, com a utilização da Álgebra de Mapas do ArcGis, gerou-se o mapa de vulnerabilidade à perda de solos.

Tabela 03 - Pesos atribuídos às variáveis para a geração da carta de Vulnerabilidade

\begin{tabular}{cc}
\hline Variável & Peso \\
\hline Geologia & 0,10 \\
Clima (Precipitação) & 0,15 \\
Solos & 0,20 \\
Uso do Solo & 0,25 \\
Geomorfologia (Declividade) & 0,30 \\
\hline
\end{tabular}

Fonte: Crepaniet al. (2001); SANTOS, M. T. P. (2019)

Revista Cerrados, Montes Claros/MG, v.17, n. 2, p. 290-311, jul./dez.-2019. 
SANTOS, M. T. P.; ALMEIDA, M. I. S.

Vulnerabilidade da paisagem à perda de solos do município de Francisco Sá - MG

\section{DISCUSSÃO E RESULTADOS}

Os resultados desta pesquisa pautaram-se nos mapas de geologia, geomorfologia, solos, vegetação/uso e ocupação da terra e dados pluviométricos. A partir da integração desses por meio da álgebra de mapas, foi originado o mapa síntese de vulnerabilidade natural da paisagem do município de Francisco Sá à perda de solo. Assim, como poderá ser observado, foram descritos os valores de vulnerabilidade atribuídos para cada elemento da paisagem, com as seguintes definições: os valores próximos a 1,0 caracterizam paisagens estáveis; próximos a 2,0 como paisagens intermediárias e os mais próximos do 3,0, como paisagens vulneráveis.

\section{Vulnerabilidade geológica}

Para a análise da vulnerabilidade geológica de uma área é considerado o grau de coesão das rochas preexistentes. Assim, rochas com maior grau de coesão são consideradas estáveis e, com menor grau, como vulneráveis (BARBOSA; LORANDI, 2012). Na área de estudo foram identificadas rochas ígneas, metamórficas e sedimentares, às quais foram atribuídos valores de acordo com seu grau de coesão, conforme disposto na Tabela 04.

\begin{tabular}{cccc}
\hline \multicolumn{4}{c}{ Tabela 04 - Pesos atribuídos à geologia do município de Francisco Sá } \\
\hline Unidades & Pesos & Área $\left(\mathbf{K m}^{\mathbf{2}}\right)$ & $\%$ \\
\hline Serra do Catuni & 2,2 & 359,2 & 13,0 \\
Rio Gorutuba & 1,1 & 37,7 & 1,4 \\
Quartzitos & 1,0 & 47,7 & 1,7 \\
Serra Santa Helena & 2,7 & 39,1 & 1,4 \\
Coberturas detríticas ferruginosas & 3,0 & 134,6 & 4,9 \\
Suíte do Itacambiruçu & 1,1 & 6,1 & 0,2 \\
Porteirinha & 2,0 & 224,6 & 8,1 \\
Lagoa do Jacaré Calcário & 2,9 & 109,1 & 4,0 \\
Lagoa do Jacaré Marga & 2,9 & 495,7 & 18,0 \\
Barrocão & 1,1 & 83,1 & 3,0 \\
Lagoa do Jacaré & 2,8 & 1209,5 & 43,8 \\
Riacho dos Machados & 1,9 & 12,7 & 0,5 \\
\hline
\end{tabular}

Fonte: SANTOS, M. T. P. (2019).

De acordo com os dados apresentados na Tabela 04, a unidade denominada de Lagoa do Jacaré e suas variações ocupam a maior área do município, seguida pela Serra do 
SANTOS, M. T. P.; ALMEIDA, M. I. S.

Vulnerabilidade da paisagem à perda de solos do município de Francisco Sá - MG

Catuni. Quanto à vulnerabilidade, observa-se na maior área a atribuição de valores que variam de intermediário a vulnerável (FIGURA02).

Figura 02 - Mapa de vulnerabilidade geológica do município de Francisco Sá

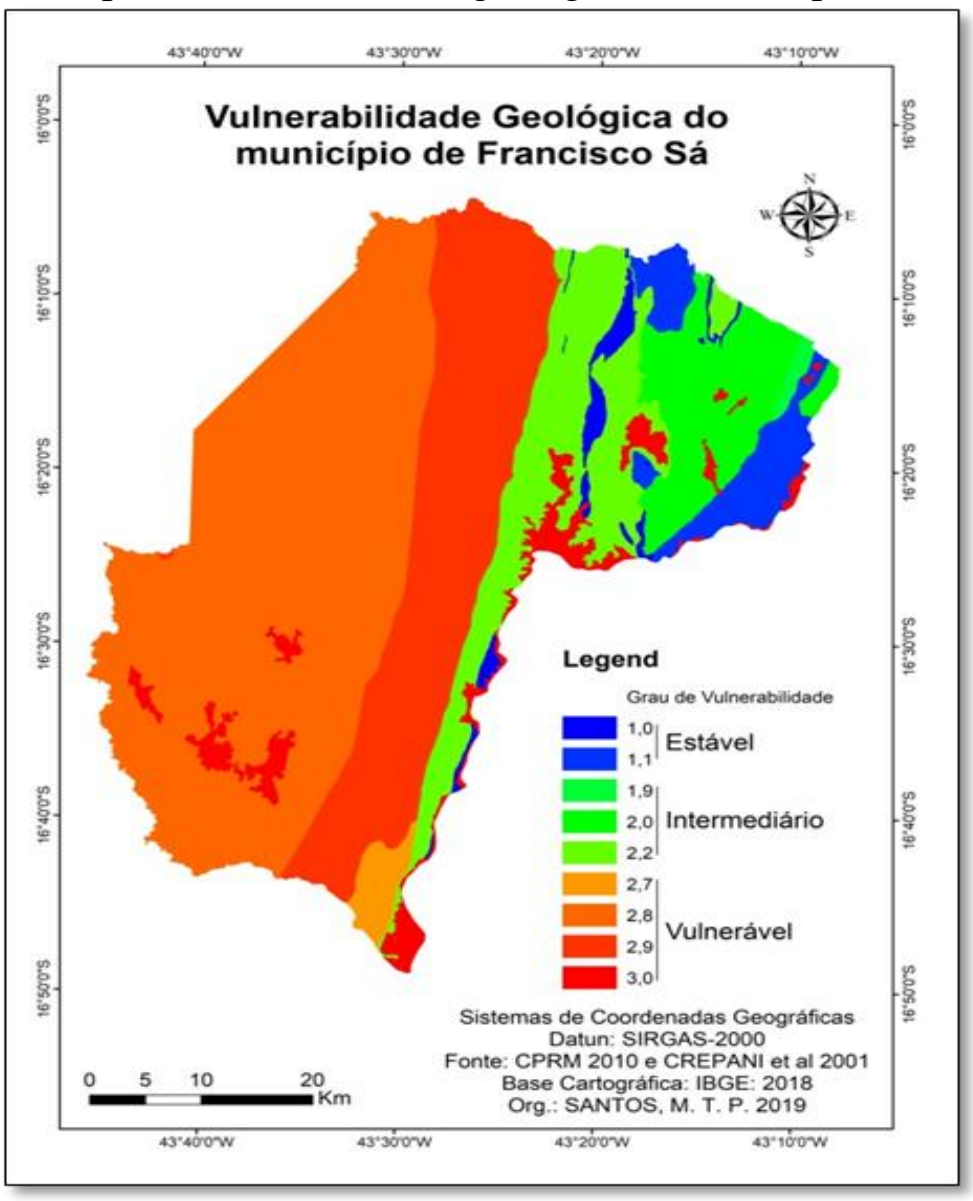

Fonte: SANTOS, M. T. P. (2019).

De acordo com a Figura 02, é possível observar uma expressiva área com vulnerabilidade geológica concentrada. Isso ocorre nas áreas de ocorrência de rochas do tipo sedimentares, devido ao menor grau de coesão que essas apresentam. As extensões de vulnerabilidade intermediárias localizam-se sobre rochas metamórficas e as de ocorrência ígneas estão classificadas como vulnerabilidade estável.

\section{Vulnerabilidade Geomorfológica}

Ao considerar a declividade da área e as unidades geomorfológicas identificadas é possível inferir que o município apresenta quatro classes de declividades. A classe 0-3\%, 
SANTOS, M. T. P.; ALMEIDA, M. I. S.

Vulnerabilidade da paisagem à perda de solos do município de Francisco Sá - MG

indica um relevo plano e a classe de 3-8\%, suave ondulado. Ambas estão localizadas na Unidade Geomorfológica denominada de Bacia Sedimentar do São Francisco. As classes de 8-20\% indicam relevo ondulado e as de $20-45 \%$, forte ondulado, localizadas nas Serras, Patamares e Escarpas do Espinhaço. Assim, a Tabela 05 mostra a distribuição das classes de declividade em áreas por $\mathrm{km}^{2}$, bem como, os pesos de vulnerabilidades atribuídos.

\begin{tabular}{cccc} 
Tabela $05-$ Pesos atribuídos à geomorfologia do município de Francis & \multicolumn{4}{c}{ Peso } & Área $\left(\mathbf{K m}^{\mathbf{2}}\right)$ & $\mathbf{\%}$ \\
\hline Classe & 1,1 & 1395,0 & 50,6 \\
$0-3 \%$ & 1,2 & 1005,8 & 36,5 \\
$3-8 \%$ & 1,7 & 339,1 & 12,3 \\
$8-20 \%$ & 2,7 & 19,0 & 0,7 \\
$20-45 \%$ &
\end{tabular}

Fonte: EMBRAPA (1979); SANTOS, M. T. P. (2019).

Conforme os dados apresentados na Tabela 05, o relevo de maior ocorrência na área de estudo é o plano, ocupando mais de $50 \%$ de sua totalidade, e o de menor é o forte ondulado. Quanto aos pesos atribuídos às classes de relevo, esses variaram de estável a vulnerável, com predominância da classe estável, conforme a Figura 03.

Figura 03 - Mapa de vulnerabilidade geomorfológica do município de Francisco Sá

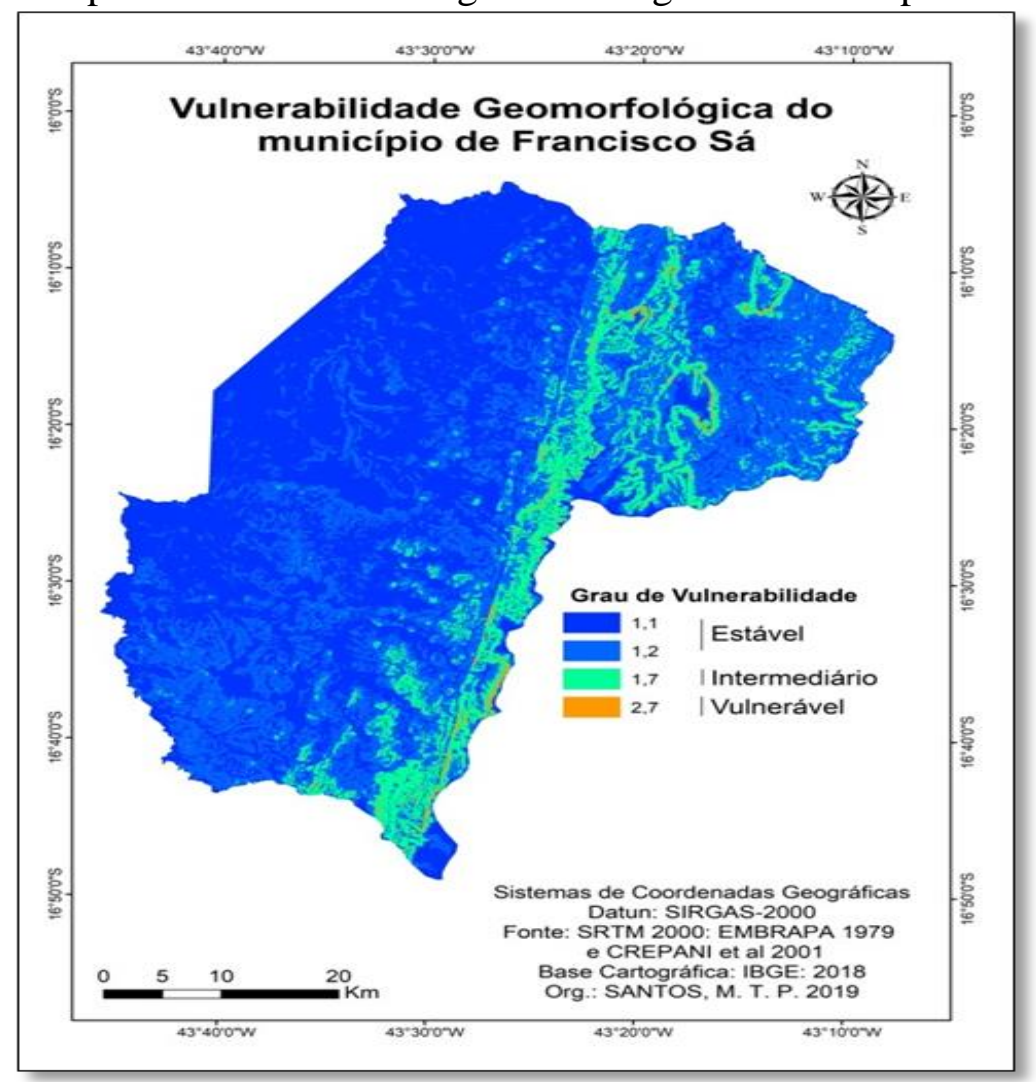

Fonte: SANTOS, M. T. P. (2019).

Revista Cerrados, Montes Claros/MG, v.17, n. 2, p. 290-311, jul./dez.-2019. 
SANTOS, M. T. P.; ALMEIDA, M. I. S.

Vulnerabilidade da paisagem à perda de solos do município de Francisco Sá - MG

A Figura 03 demonstra que a geomorfologia da área de estudo pode ser considerada estável, devido à predominância de relevos pouco movimentados, fator de elevada importância na classificação da vulnerabilidade da paisagem.

\section{Vulnerabilidade pedológica}

Para identificar a vulnerabilidade pedológica considera-se a sua suscetibilidade a ser erodidapor meio dos processos naturais do ambiente. Foram identificadas sete classes de solos,como é demostrado na Tabela 06.

Tabela 06 - Vulnerabilidade pedológica do município de Francisco Sá

\begin{tabular}{cccc} 
Classe & Vulnerabilidade & Área $\left(\mathbf{k m}^{\mathbf{2}}\right)$ & \% \\
\hline Argissolo vermelho-amarelo & 2,7 & 432,0 & 15,7 \\
Cambissolo háplico & 2,5 & 42,8 & 1,6 \\
Latossolo vermelho & 1,0 & 952,3 & 34,5 \\
Latossolo vermelho-amarelo & 1,2 & 68,9 & 2,5 \\
Neossolo flúvico & 2,9 & 6,2 & 0,2 \\
Neossolo litólico & 3,0 & 1157,6 & 42,0 \\
Nitossolo háplico & 2,8 & 99,2 & 3,6 \\
\hline
\end{tabular}

Fonte: SANTOS, M. T. P. (2019).

Os dados na Tabela 06 demonstram que a maioria dos solos são vulneráveis à erosão, com exceção dos Latossolos que se apresentam estáveis. Os valores atribuídos para a vulnerabilidade dos solos variaram de estável a vulnerável (FIGURA 04).

Considerando a Figura 04, é possível inferir que a distribuição espacial dos solos vulneráveis à erosão está situada na área de predominância de relevo mais movimentado, o que pode agravar esse processo. Os solos considerados estáveis ocorrem nas áreas com relevo mais plano. 
SANTOS, M. T. P.; ALMEIDA, M. I. S.

Vulnerabilidade da paisagem à perda de solos do município de Francisco Sá - MG

Figura 04 - Vulnerabilidade pedológica do município de Francisco Sá

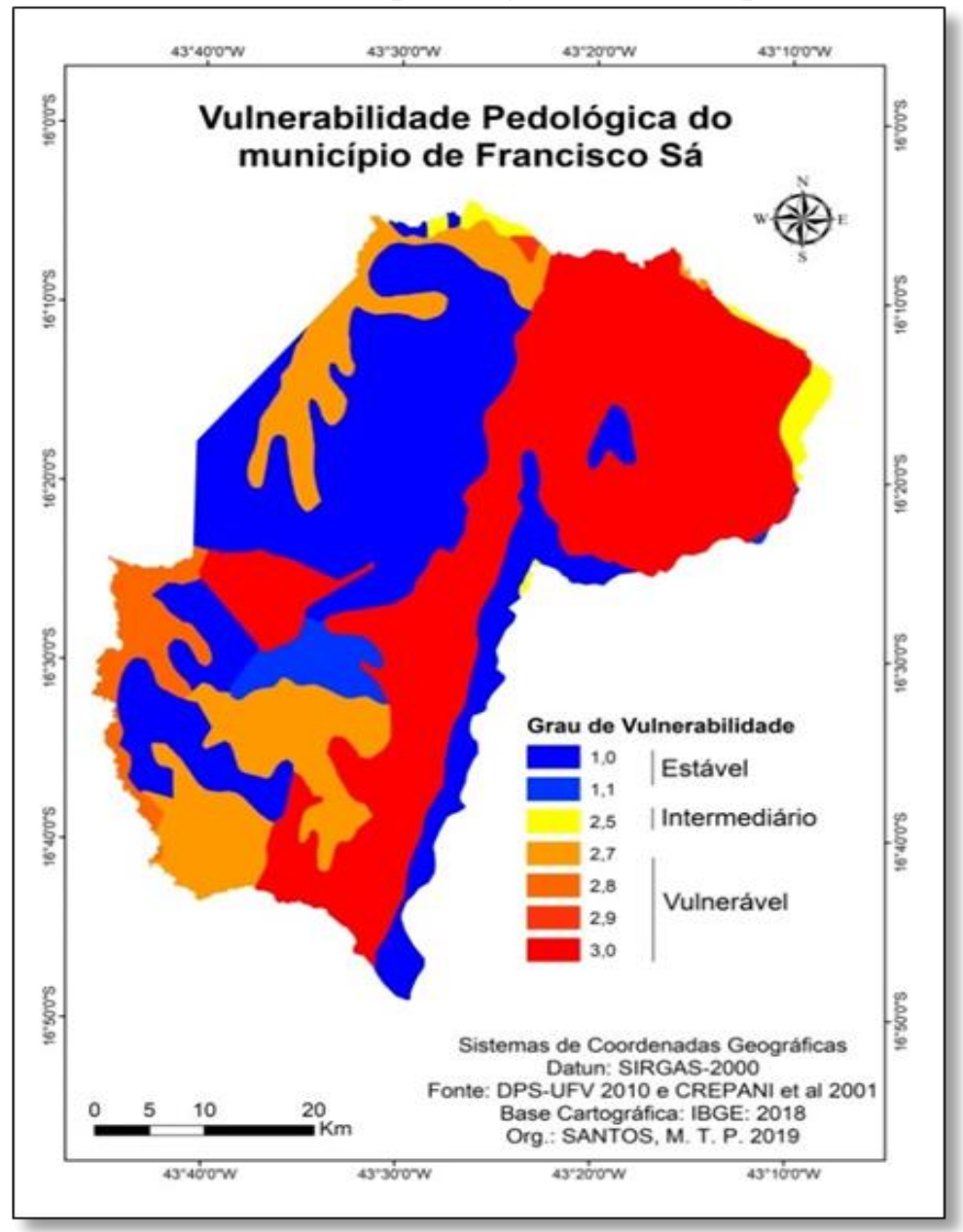

Fonte: SANTOS, M. T. P. (2019).

\section{Vulnerabilidade ao Uso do solo}

A cobertura do solo é um fator importante para a classificação da vulnerabilidade da paisagem ao processo de perda de solos, e quanto maior a densidade de cobertura vegetal, menor será o processo de erosão do solo. Foi possível apontar cinco classes de uso do solo (TABELA 07).

A Tabela 07 apresenta as classes de uso do solo e na qual se evidencia que a vegetação nativa, considerada estável, ocupa maior área de cobertura. Os pesos atribuídos às classes de uso variaram de estável a vulnerável, conforme a Figura 05: 
SANTOS, M. T. P.; ALMEIDA, M. I. S.

Vulnerabilidade da paisagem à perda de solos do município de Francisco Sá - MG

Tabela 07 - Vulnerabilidade ao uso do solo do município de Francisco Sá

\begin{tabular}{cccc}
\hline Classe & Vulnerabilidade & Área $\left(\mathbf{K m}^{2}\right)$ & $\mathbf{\%}$ \\
\hline Eucalipto & 2 & 37,4 & 1,4 \\
Vegetação Nativa & 1,2 & 1577,7 & 57,2 \\
Pasto & 2,7 & 1003,9 & 36,4 \\
Solo Exposto & 3 & 134,6 & 4,9 \\
Área Urbana & 2,5 & 5,4 & 0,2 \\
\hline
\end{tabular}

Fonte: SANTOS, M. T. P. (2019).

Figura 05 - Vulnerabilidade ao uso do solo do município de Francisco Sá

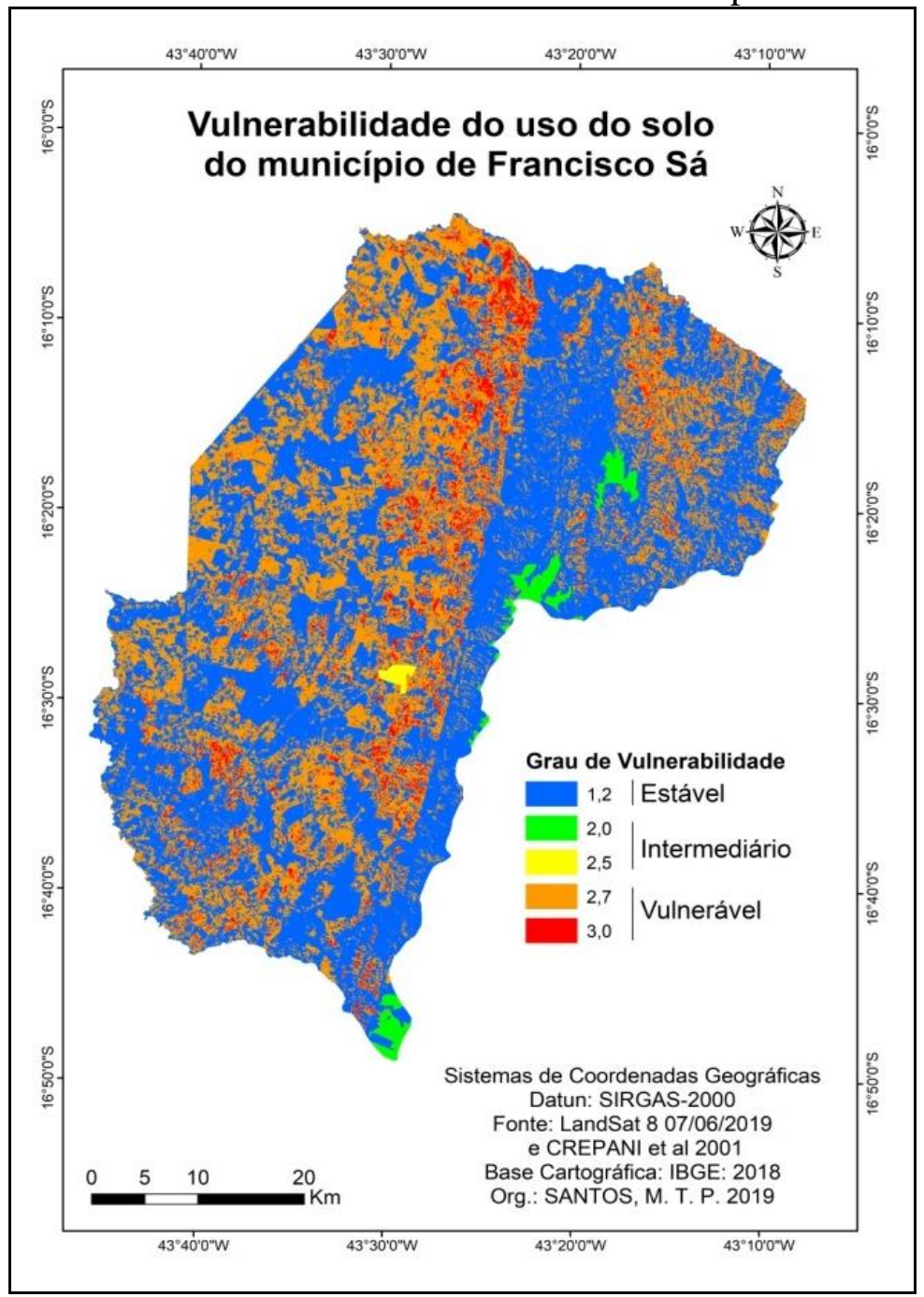

Fonte: SANTOS, M. T. P. (2019).

É possível verificar na Figura 05 que a classe considerada estável, representada pela vegetação nativa, está localizada em maior abrangência espacial em áreas de relevo mais movimentado. Isso se deve à dificuldade que o relevo apresenta para o desenvolvimento de 
SANTOS, M. T. P.; ALMEIDA, M. I. S.

Vulnerabilidade da paisagem à perda de solos do município de Francisco Sá - MG

outras atividades como a agropecuária que, em contrapartida, ocorre de forma expressiva nas áreas de relevos planos.

\section{Vulnerabilidade climática}

A variável climática para a vulnerabilidade da paisagem à perda de solos é representada pela precipitação, importante elemento nessa análise, pois exerce influência direta sobre os mesmos. Dessa forma, a depender de seu estado de cobertura, tal contexto pode causar grandes perdas de solos (NICOLAU, 2018).

De acordo com Crepani et al. (2001), o cálculo da intensidade pluviométrica é realizado por meio da expressão que divide o valor médio anual de precipitação pelo número de meses de sua maior ocorrência. Assim, para o município de Francisco Sá encontrou-se o resultado demonstrado na Tabela 08.

Tabela 08 - Intensidade pluviométrica do município de Francisco Sá

\begin{tabular}{c|c|c}
\hline $\begin{array}{c}\text { Valor médio de } \\
\text { precipitação anual* } \\
(\mathbf{m m})\end{array}$ & $\begin{array}{c}\text { Período chuvoso de maior } \\
\text { intensidade } \\
(\mathbf{m e ̂ s})\end{array}$ & $\begin{array}{c}\text { Intensidade pluviométrica } \\
(\mathbf{m m} / \mathbf{m e ̂ s})\end{array}$ \\
\hline 932,7 & 5 meses & 186,54 \\
\hline
\end{tabular}

Fonte: EMATER (2018); SANTOS, M. T. P. (2019).

*Média anual do período de 1992 a 2018.

Com o resultado obtido da intensidade mensal pluviométrica de 186,54 e considerando a classificação de Crepani et al. (2001), a vulnerabilidade recebe o valor de 1,6 configurando-se, assim, estável.

\section{Vulnerabilidade da paisagem do município de Francisco Sá à perda de Solos}

Após a determinação da vulnerabilidade de cada elemento da paisagem, foi realizado o cruzamento dos dados. Dessa forma, obteve-se a vulnerabilidade final da paisagem do município para a perda de solos, conforme a Figura 06. 
SANTOS, M. T. P.; ALMEIDA, M. I. S.

Vulnerabilidade da paisagem à perda de solos do município de Francisco Sá - MG

Figura 06 - Vulnerabilidade da paisagem do município de Francisco Sá à perda de solos

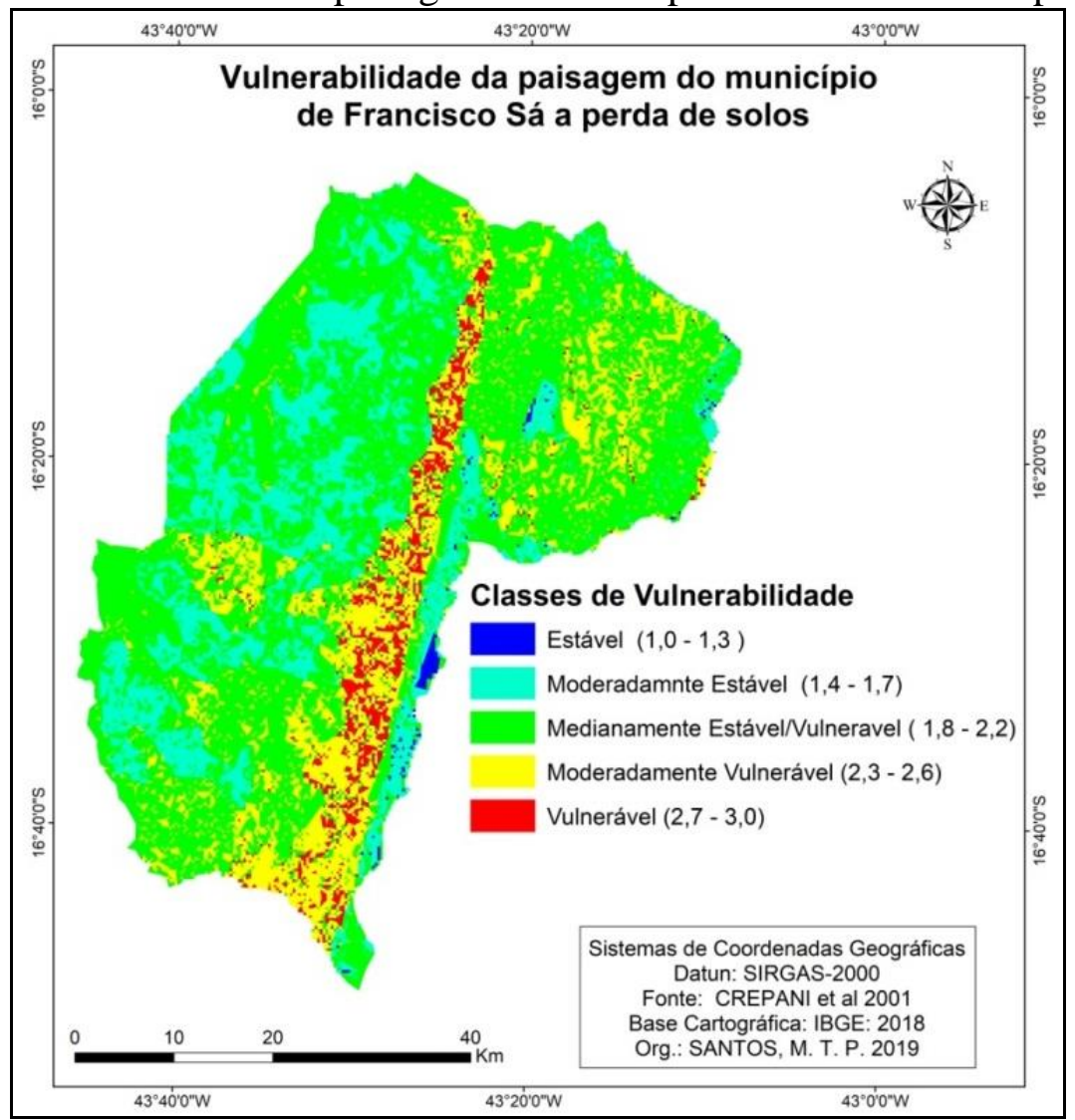

Fonte: SANTOS, M. T. P. (2019).

De acordo com a Figura 06, identificou-se cinco Unidades de Vulnerabilidade da paisagem: Estável, Moderadamente Estável, Medianamente Estável/Vulnerável, Moderadamente Vulnerável e, por último, Vulnerável. Essas Unidades ocupam áreas distintas no município, como demonstra a Tabela 09.

Tabela 09 - Vulnerabilidade da paisagem quantificada do município de Francisco Sá

\begin{tabular}{cccc}
\hline Unidade da Paisagem & Vulnerabilidade & Área $\left(\mathbf{k m}^{\mathbf{2}}\right)$ & $\mathbf{\%}$ \\
\hline Estável & $1,0-1,3$ & 19,2 & 0,7 \\
Moderadamente Estável & $1,4-1,7$ & 537,4 & 19,5 \\
Medianamente Estável/Vulnerável & $1,8-2,2$ & 1580,3 & 57,3 \\
Moderadamente Vulnerável & $2,3-2,6$ & 500,8 & 18,2 \\
Vulnerável & $2,7-3,0$ & 121,3 & 4,4 \\
\hline
\end{tabular}

Fonte: Crepani et al. (2001); SANTOS, M. T. P. (2019).

De acordo com os dados apresentados na Tabela 09 e na Figura 06, é possível fazer as seguintes inferências sobre o grau de vulnerabilidade das Unidades da Paisagem encontradas em Francisco Sá. A Unidade Estável apresenta valores de vulnerabilidade entre 1,0-1,3 e ocupa a menor área dentro dos limites do município, com apenas 19,2 Km², Revista Cerrados, Montes Claros/MG, v.17, n. 2, p. 290-311, jul./dez.-2019. 
SANTOS, M. T. P.; ALMEIDA, M. I. S.

Vulnerabilidade da paisagem à perda de solos do município de Francisco Sá - MG

o equivalente a apenas $0,7 \%$ do território. Apesar de localizada em uma área de relevo ondulado, possui litologia estável associada a solos do tipo Latossolos, bastante estáveis à erosão. Como cobertura vegetal, tem-se áreas de monoculturas medianamente estáveis/vulneráveis ou vegetação nativa, ou seja, áreas estáveis. Portanto, todos esses fatores contribuem para que essa Unidade se configure como estável para a perda de solos.

A Unidade Moderadamente Estável representa 19,5\% da área em estudo, ou seja, $537,4 \mathrm{~km}^{2}$ recebem como valores de vulnerabilidade 1,4-1,7. Predominam nessa Unidade relevos planos, com algumas áreas de relevo mais movimentado. Em relação à litologia, predomínio de áreas bastante vulneráveis, situadas sobre rochas sedimentares. Os solos predominantes são os Latossolos, ou seja, estáveis, sendo essa Unidade recoberta por vegetação nativa ou por pastagem, tornando-a uma área de estabilidade moderada para a perda de solo.

A Unidade Medianamente Estável/Vulnerável é a de maior ocorrência no município de Francisco Sá. Recebe como valores de vulnerabilidade 1,8-2,2 e ocupa uma área de $1.580,3 \mathrm{~km}^{2}$, o equivalente a $57,3 \%$ de toda a área do município. Ali se constata a predominância de relevos planos e movimentados. A geologia se divide em áreas de rochas estáveis e vulneráveis e nas quais se predominam os solos Neossolos Litólicos, extremamente expostas ao processo erosivo. Em relação à cobertura do solo, o predomínio é de vegetação nativa e algumas ocorrências de pastagens.

Todos esses fatores permitem considerar essa Unidade como uma área Medianamente Estável/Vulnerável, pois, embora apresente suas fragilidades, quando associadas a outros elementos, torna-se intermediária para a perda de solos. Nesse caso em específico, o fator de maior importância dessa área é a cobertura do solo que é estável, uma vez que, se essa for perdida, pode torná-la mais vulnerável à perda de solos, em virtude da tipologia pedológica presente.

A Unidade Moderadamente Vulnerável recebe os valores de 2,3-2,6 e ocupa $500,8 \mathrm{~km}^{2}$, ou seja, $18,2 \%$ do total da área, constituída por relevos forte ondulados. Observase, no entanto, em algumas áreas, a presença de relevos mais planos. Essa Unidade associa-se a uma geologia vulnerável e solos como o Neossolo Litólico e o Argissolo vermelho amarelo, suscetíveis à erosão. Como apresenta uma área recoberta por pastagem e ocorrência de solos expostos, a torna moderadamente vulnerável, ou seja, a partir do processo acelerado de denudação do solo, essa Unidade tende a se tornar vulnerável à perda de solo. 
SANTOS, M. T. P.; ALMEIDA, M. I. S.

Vulnerabilidade da paisagem à perda de solos do município de Francisco Sá - MG

A Unidade Vulnerável ocupa 4,4\% da área total do município, ou seja, 121,3 $\mathrm{Km}^{2}$, e para a qual atribuíram-se os valores de 2,7-3,0. Ocorre em áreas com relevo ondulado a forte ondulado e uma geologia vulnerável constituída de rochas sedimentares. Seus solos são extremamente vulneráveis e, em sua maioria, apresentam-se expostos. Em algumas, no entanto, como áreas de pastagem, tornando-a assim uma unidade vulnerável à perda de solos.

\section{CONSIDERAÇÕES FINAIS}

A determinação da vulnerabilidade da paisagem à perda de solos pode ser classificada como uma importante ferramenta na tomada de decisão para o planejamento ambiental. Isso porque ela possibilita uma melhor compreensão das características físiconaturais em áreas que necessitam de manejo adequado dos solos e, ainda, de medidas de prevenção para controle dos processos erosivos.

Assim, ao utilizar a metodologia proposta por Crepini et al. (2001) para determinar a vulnerabilidade da paisagem do município de Francisco Sá (MG),tornou-se possível afirmar que o mesmo apresenta de média a alta à perda de solos. Esse contexto denuncia a necessidade de imprescindível atenção e cuidados a serem envidados, com o propósito de serem evitados processos erosivos mais intensos no futuro.

O município de Francisco Sá ainda apresenta as seguintes características quanto à área analisada no presente estudo: geologia predominantemente vulnerável e geomorfologia estável; constituição de solos em sua maioria vulneráveis ao processo erosivo e, em sua cobertura, predomínio da classe estável. Por fim, uma intensidade pluviométrica que possibilita seja considerada estável.

Portanto, ao se associarem todos esses fatores para a análise da paisagem do município de Francisco Sá quanto à sua vulnerabilidade, é possível apontar que o fator Uso do Solo é uma variável de extrema relevância e merecedora de efetiva atenção. Essa afirmativa se baseia na verificação de que as áreas de pastagem e solo exposto correspondem a mais de $40 \%$ do Uso do Solo da área em questão o que, associado à alta vulnerabilidade dos solos para o processo erosivo, pode acarretar em eventuais problemas ambientais. 


\section{REFERÊNCIAS}

BARBOSA, Y. B.; LORANDI, R. Geoprocessamento aplicado ao estudo da vulnerabilidade à erosão na bacia hidrográfica do Ribeirão do Pântano nos municípios de São Carlos, Analândia e Descalvado (SP). Revista Geografia, Londrina, v. 21, n. 1, p. 103-123, 2012.

COSTA, F. H. S. et al. Determinação da vulnerabilidade ambiental na Bacia Potiguar, região de Macau (RN), utilizando sistemas de informações geográficas. Revista Brasileira de Cartografia, $\mathrm{n}^{\circ}$ 58/02, p.119-127, agosto, 2006.

COUTINHO, L.M. O conceito de bioma. In: Acta Botanica Brasilica:20(1), p.1-11, 2006.

Disponível em: http://www.scielo.br/scielo.php?script=sci_serial\&pid=0102$3306 \& \operatorname{lng}=$ en\&nrm=iso. Acesso em: 13 de jun. 2019.

CPRM - COMPANHIA DE PESQUISA DE RECURSOS MINERAIS.Portal do GeoBank. Disponível em:http://geosgb.cprm.gov.br/. Acesso em: 12 jun. 2019.

CREPANI E. et al.Sensoriamento Remoto e Geoprocessamento Aplicados ao Zoneamento Ecológico-Econômico e ao Ordenamento Territorial. São José dos Campos, SP: INPE, jun. 2001, 113 p.

GUERRA, A. J. T.; CUNHA, S. B. Degradação ambiental. In: CUNHA, S. B. Geomorfologia e meio ambiente. Rio de Janeiro: Bertrand Brasil, 1996. p. 337-379.

GUERRA, A. J. T.; MENDONÇA, J. K. S. Erosão dos solos e a Questão Ambiental. In: VITTE, A. C.; GUERRA, A. J. T. (orgs.). Reflexões sobre a Geografia Física no Brasil. Rio de Janeiro: Bertrand Brasil, p. 225-256, 2005.

GUIMARÃES, M.L.V.; GROSSI-SAD, J.H.; FONSECA, E.da. Geologia da Folha Francisco Sá. In: GROSSI-SAD, J. H. et al. (coords.eds.). Projeto Espinhaço. Belo Horizonte: COMIG, 1997, p. 223-313.CD-ROM(textos, mapas e anexos).

IBGE - INSTITUTO BRASILEIRO DE GEOGRAFIA E ESTATÍSTICA. Mapa de Clima do Brasil. 2002. Disponível em:

http://geoftp.ibge.gov.br/informacoes_ambientais/climatologia/mapas/brasil/Map_BR_clima 2002.pdf. Acesso em: 11 jun. 2019.

IBGE - INSTITUTO BRASILEIRO DE GEOGRAFIA E ESTATÍSTICA.Censo

Demográfico de Francisco Sá 2010. Rio de Janeiro, 2010. Disponível em:http://www.sidra.ibge.gov.br. Acesso em: 12 jun. 2019.

IGAM - INSTITUTO MINEIRO DE GESTÃO DAS ÁGUAS. Plano Estadual de Recursos Hídricos - PERH / Instituto Mineiro de Gestão das Águas. Belo Horizonte: IGAM, 2010. 518p.; il. - (Relatório final - volume I: aspectos estratégicos para a gestão de recursos hídricos de Minas Gerais). 
INPE - INSTITUTO DE PESQUISAS ESPACIAIS (Brasil). Programa LANDSAT. São José dos Campos: INPE, 2019. Disponível em:

http://www.dgi.inpe.br/documentacao/satelites/landsat. Acesso em: 26 set. 2019.

NICOLAU, R. de F. Vulnerabilidade da paisagem à perda de solos da bacia hidrográfica do rio do Peixe - Goiás. In:Caminhos de Geografia, Uberlândia- MG, v. 19, n. 66, p. 285296, julho 2018.

ROCKETT, G. C, et al.Geoprocessamento aplicado análise ambiental: vulnerabilidade natural à perda de solo no Morro do Osso, Porto Alegre/RS. Geografia, v. 39, n. 3, p. 465-481, 2014.

SANTOS, H.C.; LEITE, R.F.C. Norte de Minas múltiplos olhares sobre a ocupação do Cerrado.In: XVI ENCONTRO NACIONAL DE GEÓGRAFOS, Porto Alegre: AGB, 25-31 julho 2010. $10 \mathrm{p}$.

SCOLFORO, J. R.; MELLO, J. M.; OLIVEIRA, A. D. Inventário Florestal de Minas Gerais: Cerrado - Florística, Estrutura, Diversidade, Similaridade, Distribuição Diamétrica e de Altura, Volumetria, Tendências de Crescimento e Áreas Aptas para Manejo Florestal. Lavras: UFLA, 2006.

SILVA NETO, J. C. A. Avaliação da vulnerabilidade à perda de solos na bacia do rio Salobra, MS, com base nas formas do terreno. Geografia (Londrina), v.22, p.5-25, 2013.

SILVA NETO J. C. A.; ALEIXO, N. C. R. Análise temporal da vulnerabilidade da paisagem à perda dos solos na bacia hidrográfica do Rio Salobra - Serra da Bodoquena, Mato Grosso do Sul. Revista Formação(Online), v. 2, n. 23, p.252-270, 2016.

SUERTEGARAY, D. M; NUNES, J. O. R. A natureza da Geografia Física. Revista Terra Livre, São Paulo, n. 17, v. 1,p.11-24, $2^{\circ}$ sem. 2001.

TAGLIANI, C. R. A. Técnica para avaliação da vulnerabilidade ambiental de ambientes costeiros utilizando um Sistema Geográfico de Informações.In: Anais XI Simpósio Brasileiro de Sensoriamento Remoto - SBSR, Belo Horizonte, Brasil, INPE, p. 1657 - 1664, 2003.

TRICART, J. Ecodinâmica. Rio de Janeiro: IBGE, 1977, 91p.

VALLE JUNIOR, R. F. Diagnóstico de áreas de risco de erosão e conflito de uso dos solos na bacia do rio Uberaba. 2008. 222 f. Tese (Doutorado em Agronomia) - Faculdade de Ciências Agrárias e Veterinárias, Universidade Estadual Paulista - Júlio de Mesquita Filho, Jaboticabal, 2008. 
Maria Tereza Pereira dos Santos - Possui Graduação e Mestrado em Geografia, ambos cursados pela Universidade Estadual de Montes Claros (UNIMONTES). Atualmente é Professora da Secretaria do Estado da Educação de Minas Gerais.

Maria Ivete Soares de Almeida - Possui Graduação em Geografia pela Universidade Estadual de Montes Claros (UNIMONTES), Mestrado em Geografia pela Universidade Federal de Goiás (UFG) e Doutorado em Tratamento da Informação Espacial pela Pontifícia Universidade Católica de Minas Gerais (PUC/Minas). Atualmente é Professora do Programa de Pós-Graduação em Geografia, Departamento de Geociência da Universidade Estadual de Montes Claros (UNIMONTES).

Artigo recebido em: 24 de setembro de 2019. Artigo aceito em: 12 de dezembro de 2019. Artigo publicado em: 20 de dezembro de 2019. 